\title{
STRATEGI PEREKRUTAN ANGGOTA BARU K-LINK DI STOCKIST CENTER PADANGSIDIMPUAN
}

\author{
Nurhayati Nasution \\ PT. K-Link Internasional \\ Stockist Center Padangsidimpuan \\ Email : Nurhayati_nst@gmail.com
}

\begin{abstract}
Abstrak
Pemasaran disetiap jasa memerlukan cara-cara yang berlainan. Seorang manager pemasaran harus mampu memiliki cara-cara yang tepat untuk suatu produk tertentu. Perekrutan yang baik memerlukan keterampilan, keahlian dan seni untuk mengambil keputusan mengenai cara-cara mana yang perlu digunakan dalam melakukan strategi perekrutan dengan keahlian mengkonsumsi kebijakan strategi perekrutan.

Tujuan penelitian ini adalah untuk mengetahui strategi perekrutan di Stockist Center Padangsidimpuan, untuk mengetahui anggota baru K-link di Stockist Center Padangsidimpuan dan untuk mengetahui apakah ada pengaruh strategi perekrutan dengan anggota baru K-link di Stockist Center Padangsidimpuan.

Adapun bentuk penelitian yang digunakan adalah metode penelitian deskriptif dengan pendekatan analisis deskriptif kuantitatif untuk mengolah data-data yang diperoleh dari lokasi penelitian.

Hasil penelitian tentang strategi perekrutan anggota baru diketahui bahwa sebanyak 105 jawaban responden memilih Sangat puas, memilih Puas sebanyak 199 jawaban, Cukup puas sebanyak 124 jawaban, Kurang puas sebanyak 66 jawaban dan Tidak puas sebanyak 26. Dengan demikian dapat disimpulkan bahwa responden lebih banyak menjawab cukup puas dengan demikian strategi perekrutan anggota baru memuaskan.
\end{abstract}

Kata kunci: K-Link, Rekrutmen, Strategi, Stockist

\begin{abstract}
Marketing in each service requires different ways. A marketing manager must be able to have the right methods for a particular product. Good recruitment requires the skills, expertise and art to make decisions about which methods need to be used in carrying out recruitment strategies with the expertise to consume recruitment strategy policies. The purpose of this study was to find out the recruitment strategies at Padangsidimpuan Stockist Center, to find out new K-link members at the Padangsidimpuan Stockist Center and to find out whether there was any influence on the recruitment strategy with new K-link members at Padangsidimpuan Stockist Center.

The form of research used is descriptive research method with a quantitative descriptive analysis approach to process the data obtained from the research location.

The results of the research on recruitment strategies for new members revealed that as many as 105 respondents chose Very satisfied, voted Satisfied as many as 199 answers, Quite satisfied as many as 124 answers, Less satisfied as many as 66 answers and Dissatisfied as much as 26 . Thus it can be concluded that respondents answered more thus satisfied the new member recruitment strategy is satisfying.
\end{abstract}

Keywords: K-Link, Recruitment, Strategy, Stockists

\section{PENDAHULUAN}

Membicarakan perekrutan calon anggota baru berarti membicarakan bagaimana pengaruh komunikasi yang baik dan mudah dimengerti dalam memperospek calon anggota baru serta bagaimana relevansi keduanya. Dengan penggunaan komunikasi yang baik dan mudah dimengerti akan mempermudah pelaksanaan perekrutan. 
Penerapan strategi perekrutan pada jalur pemasaran akan membantu pemasar dalam menarik minat konsumen dan mempertahankan konsumen yang berimbas pada peningkatan penjualan dan juga penciptaan citra yang baik bagi perusahaan. Pesatnya perkembangan bisnis mempengaruhi perkembangan perekrutan yang cukup signifikan. Salah satunya adalah rencana pemasaran merupakan peranan penting dalam keberhasilan suatu perusahaan.

Di Indonesia K-link didirikan pada 22 Mei 2002 dengan kantor awal dikawasan Mal Mangga Dua Jakarta Barat.. Jika K-link Internasional telah melebarkan sayap perniagaannya sampai ke 25 (dua puluh lima) negara, maka K-link Indonesia telah menjangkau seluruh pelosok Indonesia dengan 33 (tiga puluh tiga) provinsi. Sedangklan K-link di Padangsidimpuan dikenal tahun 2007 dan stockistnya berdiri pada tanggal 18 Juni 2010.

Stockist adalah tempat penyedia barang untuk memudahkan mitra mendapatkan barang dan kegiatan administrasi mitra dengan persyaratan memiliki ruko dua lantai, lantai satu untuk kegiatan mitra, penyimpanan produk, lantai dua untuk kegiatan mitra K-link dan setiap transaksi omset per bulan mendapat komisi dari K-link pusat.

Stockist merupakan perpanjangan tangan dan wakil K-link di kota setempat, sebagaimana stockist senantiasa menjadi tempat pertemuan untuk training-training dan Business Opprtunity Presentation (BOP) di kota setempat.

Berdasarkan pemaparan di atas maka judul penelitian ini adalah "Strategi Perekrutan Anggota Baru K-link Di Stockist Center Padangsidimpuan".

Adapun yang menjadi perumusan masalah di sini adalah sebagai berikut:

1. Bagaimana strategi perekrutan di Stockist Center Padangsidimpuan?

2. Bagaimana anggota baru K-link di Stockist Center Padangsidimpuan?

3. Apakah ada pengaruh strategi perekrutan dengan anggota baru K-link di Stockist Center Padangsidimpuan?

\section{Pengertian Strategi}

Menurut Kamus Lengkap Bahasa Indonesia "strategi adalah cara/siasat perang”(1998:527).Sedangkan menurut Pandji Anoraga yang mengutip pendapat Uswatun Zambroni "Strategi adalah pola sasaran, maksud atau tujuan dan kebijakan serta rencana-rencana penting untuk mencapai tujuan itu, yang dinyatakan dengan cara seperti menetapkan bisnis yang dianut atau yang akan dianut oleh perusahaan, dan jenis atau akan menjadi jenis apa perusahaan ini" (2011:358).

Bernardine R. Wirjana (2007:34) mengemukakan bahwa "Strategi yang diambil untuk mencapai tujuan harus tepat dan jelas. Bila strategi tidak tepat dan kabur, maka meskipun organisasi melakukan berbagai kegiatan, tetapi sasaran tidak tercapai", maka disimpulkan bahwa strategi adalah keputusan dan tindakan yang dapat digunakan untuk melakukan keinginan dalam mencapai target atau sasaran tertentu.

\section{Rekrutmen}

Rekrutmen adalah suatu cara untuk mencari pekerja menjadi karyawan atau pegawai suatu organisasi. Sebagaimana yang dikemukakan oleh Edy Sutrisno (2011:45) "Rekrutmen merupakan suatu proses mencari, mengadakan, menemukan, dan menarik para pelamar untuk dipekerjakan dalam suatu organisasi". Sedangkan lke Kusdyah Rachmawati mengatakan bahwa "Rekrutmen merupakan serangkaian kegiatan mencari dan memikat pelamar kerja dengan motivasi, kemampuan, keahlian dan pengetahuan yang diperlukan untuk menutupi kekurangan yang diidentifikasi dalam perencanaan kepegawaian."(2008:84)

Dari pengertian di atas dapat disimpulkan bahwa rekrutmen adalah suatu cara yang dilakukan sebuah organisasi untuk mengisi posisi kekurangan karyawan yang memiliki motivasi, kemampuan, keahlian dan pengetahuan.

Multi Level Marketing (MLM) PT. K-LINK

Distributor MLM dalam menjalankan strategi pemasaran secara bertingkat dituntut memiliki kemampuan untuk 
mempengaruhi orang lain agar mau bergabung bersama-sama dalam menjalankan usaha MLM.

Sistem pemasaran yang diterapkan oleh PT.K-LINK dibuat dengan jelas, relatif sederhana, mudah, rasional dalam pelaksanaannya. PT. K-LINK memberikan bonus kepada setiap anggota yang berhasil melakukan penjualan produk-produk dan memenuhi target, maka setiap anggota PT.K-LINK harus berusaha melakukan perekrutan sebanyak-banyaknya dan juga melakukan follow up terhadap member baru agar tercapai Group Bonus Value (GBV) yang diinginkan.

\section{Stockist Center}

Stockist Center adalah tempat penjualan produk-produk milik pihak perusahaan kepada para distributor dan tempat diselengarakannya kegiatan modulmodul K-system, beberapa persyaratan yang harus dipenuhi oleh pemohon sebagal berikut:

1. Telah terdaftar sebagai distributor K-Link dan aktif menjalankan kegiatan usaha MLM K-Link.

2. Dapat berbentuk perseorangan atau badan hukum.

3. Memahami ketentuan kode etik distributor, ketentuan dan peraturan pengelolaan stockist.

4. Pemohon pengajuan stockist center minimal harus berperingkat Manager (15\%)

5. Pernah mengikuti training Best Of The Best (BOB) dan Training The Presenter (TTP)

6. Tidak menjalankan Multi Level Marketing (MLM) lain.

\section{Ketentuan Keanggotaan}

Hal ini berlaku untuk seluruh anggota $K$ link dimanapun berada tanpa terkecuali, ketentuannya adalah sebagai berikut:

1. Setiap distributor hanya diperbolehkan mempunyai 1 (satu) nomor keanggotaan.

2. Hak keanggotaan hanya milik distributor yang bersangkutan dan tidak bisa digunakan oleh orang lain kecuali suami/istri yang bersangkutan.

3. Keanggotaan sebagai distributor berlaku seumur hidup selama yang bersangkutan dapat memenuhi jumlah Business Value
(BV) minimal yang ditentukan perusahaan dalam satu tahun.

4. Seorang distributor bertanggung jawab penuh terhadap segala keputusan bisnis yang diambilnya serta segala bentuk pengeluaran yang telah dilakukannya.

5. Distributor dapat mengembangkan jaringannya diwilayah negara lain atas persetujuan perusahaan dan yang bersangkutan harus mematuhi serta bertanggung jawab terhadap segala ketentuan yang berlaku di negara tujuan termasuk pengurusan ijin-ijin dan lain sebagainya.

6. Distributor tidak dibenarkan menggunakan nama orang lain ataupun nama fiktif untuk pendaftaran keanggotaannya.

\section{METODE PENELITIAN}

Adapun bentuk penelitian yang digunakan adalah metode penelitian deskriptif dengan pendekatan analisis deskriptif kuantitatif.

Sedangkan populasi dalam penelitian ini adalah seluruh anggota baru sebanyak 87, dan sampel diambil disaat adanya perekrutan anggota baru oleh Mitra di Stockist Center sebanyak 52 orang.

Untuk mendapatkan batasan yang jelas dari setiap konsep yang diteliti maka penulis mengemukakan defenisi konsep sebagai berikut:

1. Variabel $X$, yaitu strategi perekrutan anggota baru dengan indikator karakteristik organisasi, tujuan dan kebijakan organisasi, kondisi lingkungan eksternal organisasi, biaya rekrutmen organisasi, kompensasi.

2. Variabel $Y$, yaitu anggota baru dengan indikator syarat dan prosedur perekrutan, biaya administrasi, biaya perekrutan.

Sebagai pelengkap dalam pembahasan ini maka diperlukan adanya data atau informasi baik dari dalam perusahaan maupun dari luar perusahaan. Penulis memperoleh data yang berhubungan dengan menggunakan metode sebagai berikut:

1. Studi Kepustakaan (Library Research,

2. Studi Lapangan, dan

3. Angket.

Analisis Kuantitatif menggunakan datadata yang dinyatakan dalam bentuk angka di mana data tersebut merupakan variabel- 
variabel yang dianggap berpengaruh terhadap strategi perekrutan anggota baru K-link di Stockist Center Padangsidimpuan yang pada akhirnya akan menjadi total skor dari pengisian kuesioner oleh responden.

Teknik penentuan skor yang dilakukan dalam penelitian ini adalah dengan kriteria sebagai berikut:

1. Sangat puas diberi skor 5

2. Puas diberi skor 4

3. Cukup puas diberi skor 3

4. Kurang puas diberi skor 2

5. Tidak puas diberi skor 1

Untuk menguji hipotesis digunakan rumus korelasi Product Moment sebagai berikut:

$$
r_{x y}=\frac{n\left(\sum X Y\right)-\left(\sum X\right)\left(\sum Y\right)}{\sqrt{\left.\left\{N \cdot \sum X^{2}-\left(\sum X\right)^{2}\right\} N \cdot \sum Y^{2}-\left(\sum Y\right)^{2}\right\}}}
$$

\section{Keterangan:}

$$
\begin{array}{ll}
r_{x y} & =\text { Koefisien korelasi yang dicari } \\
N & =\text { banyak subjek pemilik nilai } \\
X & =\text { nilai variabel } 1 \\
Y & =\text { Nilai variabel } 2
\end{array}
$$

Menurut Riduwan bahwa "Korelasi Pearson Product Moment ( $r$ ) dengan ketentuan nilai $r$ tidak lebih dari harga $(-1 \leq r \leq+1)$. Apabila $r=-1$ artinya korelasinya negatif sempurna, $r=0$ artinya tidak ada korelasi, dan $r=1$ berarti korelasinya sempurna positif (sangat kuat)." $(2010 ; 38)$

Sedangkan arti harga $r$ akan dikonsultasikan dengan tabel interpretasi nilai $r$ sebagai berikut:

Tabel Interpretasi Koefisien Korelasi Nilai $r$

\begin{tabular}{|c|c|}
\hline Interval Koefisien & Tingkat Hubungan \\
\hline $0,80-1,00$ & Sangat Kuat \\
\hline $0,60-0,799$ & Kuat \\
\hline $0,40-0,599$ & Cukup Kuat \\
\hline $0,20-0,399$ & Rendah \\
\hline $0,00-0,199$ & Sangat Rendah \\
\hline
\end{tabular}

Hipotesis pengujian dalam penelitian ini adalah:

$\mathrm{Ha}=$ Ada hubungan strategi perekrutan dengan anggota baru K-link di Stockist Center Padangsidimpuan.

$\mathrm{Ho}=$ Tidak ada hubungan strategi perekrutan dengan anggota baru $K$ link di Stockist Center Padangsidimpuan.

Dengan kaidah pengujian
$\mathrm{Ha}: r \neq 0$

$\mathrm{H}_{0}: r=0$

\section{HASIL DAN PEMBAHASAN Strategi Perekrutan Anggota Baru (Variabel X)}

Dari angket strategi perekrutan anggota baru yang disebarkan kepada sampel di atas, maka dapat diuraikan beberapa pertanyaan dan sistematika penilaian skor dari jawaban responden tersebut.

a. Angket memiliki 10 pertanyaan.

b. Ketentuan jawaban angket terdiri dari 5 pilihan yaitu : sangat puas, puas, cukup puas, kurang puas, tidak puas.

c. Skor penilaian adalah :

6. Sangat puas diberi skor 5

7. Puas diberi skor 4

8. Cukup puas diberi skor 3

9. Kurang puas diberi skor 2

10. Tidak puas diberi skor 1.

Untuk mencari persentase jawaban angket responden digunakan rumus persentase $P=\frac{f}{N} x 100 \%$

Keterangan:

P : Persentase

f : : Frekuensi

$\mathrm{N}$ : Jumlah responden

100\% : Bilangan tetap

Berdasarkan data jawaban responden atas semua item pertanyaan yang ada dalam

\begin{tabular}{|c|c|c|c|c|c|c|c|}
\hline \multirow{2}{*}{$\begin{array}{l}\text { No } \\
\text { Urut }\end{array}$} & \multirow{2}{*}{$\begin{array}{c}\text { No. } \\
\text { Angket }\end{array}$} & \multicolumn{5}{|c|}{ OPTION } & \multirow{2}{*}{$\begin{array}{l}\text { Jumlah } \\
\text { Responden }\end{array}$} \\
\hline & & $\begin{array}{l}\text { Sangat } \\
\text { Puas }\end{array}$ & Puas & $\begin{array}{l}\text { Cukup } \\
\text { Puas }\end{array}$ & $\begin{array}{c}\text { Kurang } \\
\text { Puas }\end{array}$ & $\begin{array}{l}\text { Tidak } \\
\text { Puas }\end{array}$ & \\
\hline 1 & 1 & 14 & 17 & 13 & 5 & 3 & 52 \\
\hline 2 & 2 & 12 & 18 & 13 & 5 & 4 & 52 \\
\hline 3 & 3 & 11 & 18 & 12 & 9 & 2 & 52 \\
\hline 4 & 4 & 9 & 19 & 13 & 8 & 3 & 52 \\
\hline 5 & 5 & 11 & 20 & 11 & 8 & 2 & 52 \\
\hline 6 & 6 & 8 & 22 & 12 & 7 & 3 & 52 \\
\hline 7 & 7 & 9 & 19 & 14 & 7 & 3 & 52 \\
\hline 8 & 8 & 10 & 18 & 15 & 7 & 2 & 52 \\
\hline 9 & 9 & 11 & 26 & 10 & 4 & 1 & 52 \\
\hline 10 & 10 & 10 & 22 & 11 & 6 & 3 & 52 \\
\hline \multicolumn{2}{|c|}{ Jumlah } & 105 & 199 & 124 & 66 & 26 & 520 \\
\hline \multicolumn{2}{|c|}{ Persentase } & $20,19 \%$ & $38,27 \%$ & $23,85 \%$ & $12,69 \%$ & $5,00 \%$ & $100,00 \%$ \\
\hline
\end{tabular}
angket, maka dapat penulis uraikan rekapitulasi hasil jawaban dan skor angketnya, yaitu :

Tabel 1 Rekapitulasi Hasil Jawaban Angket Tentang Stategi Perekrutan Anggota Baru 
Sumber: Angket Penelitian Tahun 2017

Dari data rekapitulasi hasil jawaban angket tentang strategi perekrutan anggota baru di atas dapat diketahui bahwa sebanyak 105 jawaban responden memilih Sangat puas, memilih Puas sebanyak 19 jawaban, Cukup puas sebanyak 124 jawaban, Kurang puas sebanyak 66 jawaban dan Tidak puas sebanyak 26. Dengan demikian dapat disimpulkan bahwa responden lebih banyak menjawab cukup puas dengan demikian strategi perekrutan anggota baru memuaskan.

Dari hasil penelitian diperoleh:

\section{Nilai tertinggi}

$$
=42
$$

Nilai terrendah

Rentang

Interval

$$
=29
$$$$
=42-29=13
$$$$
=\frac{R}{5}
$$

$$
=\frac{13}{5}
$$$$
=2,6
$$

dibulatkan menjadi 3

Dari hasil tersebut dibuat tabel interval sebagai berikut:

Tabel 2 Tabel Interval Angket Tentang

\begin{tabular}{|c|c|c|}
\hline Interval & Frekuensi & Persentase (\%) \\
\hline $29-32$ & 7 & 13,46 \\
\hline $33-36$ & 24 & 46,15 \\
\hline $37-40$ & 20 & 38,46 \\
\hline $41-44$ & 1 & 1,92 \\
\hline & 52 & 100 \\
\hline
\end{tabular}
Strategi Perekrutan Anggota Baru

Sumber: Angket Penelitian Tahun 2017

\section{Data Responden Tentang Anggota Baru (Variabel Y)}

Dari angket anggota baru yang disebarkan kepada sampel di atas, maka dapat diuraikan beberapa pertanyaan dan sistematika penilaian skor dari jawaban responden tersebut.
a. Angket memiliki 10 pertanyaan.
b. Ketentuan jawaban angket terdiri dari 5 pilihan yaitu : sangat puas, puas, cukup puas, kurang puas, tidak puas.
c. Skor penilaian adalah :

1. Sangat puas diberikan skor 5 ,

2. Puas diberikan skor 4 ,

3. Cukup puas diberikan skor 3 ,

4. Kurang puas diberikan sekor 2, dan

5. Tidak puas diberikan sekor 1 . Untuk mencari persentase jawaban angket responden digunakan rumus persentase $P=\frac{f}{N} x 100 \%$

Keterangan:

$P \quad$ : Persentase

f : Frekuensi

$\mathrm{N}$ : Jumlah responden

100\% : Bilangan tetap

Adapun data yang diperoleh dari penyebaran angket kepada responden yaitu:

Berdasarkan data jawaban responden atas semua item pertanyaan yang ada dalam angket, maka dapat penulis uraikan rekapitulasi hasil jawaban dan skor angketnya, yaitu :

\begin{tabular}{|c|c|c|c|c|c|c|c|}
\hline \multirow{2}{*}{$\begin{array}{l}\text { No } \\
\text { Urut }\end{array}$} & \multirow{2}{*}{$\begin{array}{c}\text { No. } \\
\text { Angket }\end{array}$} & \multicolumn{5}{|c|}{ OPTION } & \multirow{2}{*}{$\begin{array}{l}\text { Jumlah } \\
\text { Responden }\end{array}$} \\
\hline & & $\begin{array}{l}\text { Sangat } \\
\text { Puas }\end{array}$ & Puas & $\begin{array}{l}\text { Cukup } \\
\text { Puas }\end{array}$ & $\begin{array}{l}\text { Kurang } \\
\text { Puas }\end{array}$ & $\begin{array}{l}\text { Tidak } \\
\text { Puas }\end{array}$ & \\
\hline 1 & 1 & 9 & 13 & 19 & 8 & 3 & 52 \\
\hline 2 & 2 & 7 & 18 & 18 & 7 & 2 & 52 \\
\hline 3 & 3 & 8 & 15 & 16 & 9 & 4 & 52 \\
\hline 4 & 4 & 4 & 22 & 11 & 13 & 2 & 52 \\
\hline 5 & 5 & 5 & 15 & 14 & 13 & 5 & 52 \\
\hline 6 & 6 & 4 & 20 & 11 & 15 & 2 & 52 \\
\hline 7 & 7 & 4 & 18 & 17 & 11 & 2 & 52 \\
\hline 8 & 8 & 4 & 24 & 12 & 8 & 4 & 52 \\
\hline 9 & 9 & 5 & 21 & 15 & 9 & 2 & 52 \\
\hline 10 & 10 & 8 & 18 & 14 & 9 & 3 & 52 \\
\hline \multicolumn{2}{|c|}{ Jumlah } & 58 & $\begin{array}{c}18 \\
4\end{array}$ & 147 & 102 & 29 & 520 \\
\hline \multicolumn{2}{|c|}{ Persentase } & $11,15 \%$ & $\begin{array}{l}35,3 \\
8 \%\end{array}$ & $28,27 \%$ & $19,02 \%$ & $5,58 \%$ & $100,00 \%$ \\
\hline
\end{tabular}

Tabel 3 Rekapitulasi Hasil Jawaban Angket Tentang Anggota Baru

Sumber: Angket Penelitian Tahun 2017

Dari data rekapitulasi hasil jawaban angket tentang angota baru di atas dapat disimpulkan bahwa responden lebih banyak menjawab cukup puas dengan demikian anggota baru merasa puas akan mitra $\mathrm{K}$ Link.

Dari hasil penelitian diperoleh:
Nilai tertinggi $=38$
Nilai terrendah $=26$
Rentang$$
=38-26=12
$$ 
Interval

$$
\begin{aligned}
& =\frac{R}{5} \\
& =\frac{12}{5} \\
& =2,4
\end{aligned}
$$

dibulatkan menjadi 2

Dari hasil tersebut dibuat tabel interval sebagai berikut:

\begin{tabular}{|c|c|c|c|}
\hline \multicolumn{2}{|c|}{ Interval } & Frekuensi & Persentase (\%) \\
\hline 26 & -28 & 6 & 11,54 \\
\hline 29 & -32 & 21 & 40,38 \\
\hline 33 & -36 & 17 & 32,69 \\
\hline 37 & - 40 & 8 & 15,38 \\
\hline Jur & nlah & 52 & 100 \\
\hline
\end{tabular}

Tabel 4 Tabel Interval Angket Tentang Anggota Baru

Sumber: Angket Penelitian Tahun 2017

Untuk melakukan pengujian hipotesis dalam penelitian ini, penulis menggunakan teknik korelasi Product Moment yaitu:

$r_{x y}=\frac{N \sum X Y-\left(\sum X\right)\left(\sum Y\right)}{\sqrt{\left\{N \sum X^{2}-\left(\sum X\right)^{2}\right\}\left\{N \sum Y^{2}-\left(\sum Y\right)^{2}\right\}}}$

Keterangan:

$\mathrm{N} \quad=$ Banyak data

$\Sigma X Y=$ Jumlah hasil perkalian antara skor $X$ dan skor $Y$

$\sum X=$ Jumlah seluruh skor $X$

$\sum Y=$ Jumlah seluruh skor $Y$.

Untuk memperoleh harga indeks korelasi product moment $r_{x y}$ dilakukan perhitungan seperti tabel berikut :

Tabel 5 Tabel Angka Indeks Korelasi Product Moment

\begin{tabular}{|c|c|c|c|c|c|}
\hline No & $X$ & $Y$ & $X^{2}$ & $Y^{2}$ & $X Y$ \\
\hline$(1)$ & $(2)$ & $(3)$ & $(4)$ & $(5)$ & $(6)$ \\
\hline 1 & 34 & 32 & 1156 & 1024 & 1088 \\
\hline 2 & 36 & 33 & 1296 & 1089 & 1188 \\
\hline 3 & 36 & 33 & 1296 & 1089 & 1188 \\
\hline 4 & 38 & 36 & 1444 & 1296 & 1368 \\
\hline 5 & 36 & 37 & 1296 & 1369 & 1332 \\
\hline 6 & 40 & 38 & 1600 & 1444 & 1520 \\
\hline 7 & 34 & 31 & 1156 & 961 & 1054 \\
\hline 8 & 35 & 32 & 1225 & 1024 & 1120 \\
\hline
\end{tabular}

\begin{tabular}{|c|c|c|c|c|c|}
\hline 9 & 34 & 28 & 1156 & 784 & 952 \\
\hline 10 & 30 & 27 & 900 & 729 & 810 \\
\hline 11 & 29 & 28 & 841 & 784 & 812 \\
\hline 12 & 32 & 31 & 1024 & 961 & 992 \\
\hline 13 & 35 & 32 & 1225 & 1024 & 1120 \\
\hline 14 & 34 & 32 & 1156 & 1024 & 1088 \\
\hline 15 & 34 & 29 & 1156 & 841 & 986 \\
\hline 16 & 33 & 30 & 1089 & 900 & 990 \\
\hline 17 & 33 & 26 & 1089 & 676 & 858 \\
\hline 18 & 30 & 29 & 900 & 841 & 870 \\
\hline 19 & 37 & 35 & 1369 & 1225 & 1295 \\
\hline 20 & 38 & 35 & 1444 & 1225 & 1330 \\
\hline 21 & 37 & 31 & 1369 & 961 & 1147 \\
\hline 22 & 40 & 37 & 1600 & 1369 & 1480 \\
\hline 23 & 39 & 32 & 1521 & 1024 & 1248 \\
\hline 24 & 35 & 31 & 1225 & 961 & 1085 \\
\hline 25 & 39 & 34 & 1521 & 1156 & 1326 \\
\hline 26 & 34 & 31 & 1156 & 961 & 1054 \\
\hline 27 & 34 & 32 & 1156 & 1024 & 1088 \\
\hline 28 & 39 & 32 & 1521 & 1024 & 1248 \\
\hline 29 & 33 & 32 & 1089 & 1024 & 1056 \\
\hline 30 & 39 & 32 & 1521 & 1024 & 1248 \\
\hline 31 & 33 & 36 & 1089 & 1296 & 1188 \\
\hline 32 & 34 & 37 & 1156 & 1369 & 1258 \\
\hline 33 & 35 & 32 & 1225 & 1024 & 1120 \\
\hline 34 & 39 & 37 & 1521 & 1369 & 1443 \\
\hline 35 & 37 & 33 & 1369 & 1089 & 1221 \\
\hline 36 & 39 & 37 & 1521 & 1369 & 1443 \\
\hline 37 & 39 & 35 & 1521 & 1225 & 1365 \\
\hline 38 & 42 & 33 & 1764 & 1089 & 1386 \\
\hline 39 & 39 & 34 & 1521 & 1156 & 1326 \\
\hline 40 & 36 & 34 & 1296 & 1156 & 1224 \\
\hline 41 & 33 & 27 & 1089 & 729 & 891 \\
\hline 42 & 37 & 33 & 1369 & 1089 & 1221 \\
\hline 43 & 35 & 32 & 1225 & 1024 & 1120 \\
\hline 44 & 40 & 34 & 1600 & 1156 & 1360 \\
\hline 45 & 31 & 28 & 961 & 784 & 868 \\
\hline 46 & 35 & 37 & 1225 & 1369 & 1295 \\
\hline 47 & 29 & 35 & 841 & 1225 & 1015 \\
\hline 48 & 39 & 38 & 1521 & 1444 & 1482 \\
\hline 49 & 39 & 34 & 1521 & 1156 & 1326 \\
\hline 50 & 37 & 35 & 1369 & 1225 & 1295 \\
\hline 51 & 34 & 32 & 1156 & 1024 & 1088 \\
\hline 52 & 32 & 29 & 1024 & 841 & 928 \\
\hline Jumlah & 1851 & 1700 & 66381 & 56046 & 60804 \\
\hline & & & & & \\
\hline 32
\end{tabular}

Berdasarkan data pada tabel angka indeks korelasi Product Moment 
perbandingan strategi perekrutan anggota terhadap anggota baru, diperoleh hasil sebagai berikut :
$\sum X=1851$
$\sum Y=1700$
$\sum X^{2}=66381$
$\sum Y^{2}=56046$
$\sum X Y=60804$

Dengan mendistribusikan nilai-nilai di atas ke dalam rumus korelasi Product Moment diperoleh sebagai berikut :

$$
r_{x y}=\frac{N \sum X Y-\left(\sum X\right)\left(\sum Y\right)}{\sqrt{\left\{N \sum X^{2}-\left(\sum X\right)^{2}\right\}\left\{N \sum Y^{2}-\left(\sum Y\right)^{2}\right\}}}
$$

$\frac{r_{x y}}{\sqrt{\left\{52(66381)-(1851)^{2}\right\}\left\{52(56046)-(1700)^{2}\right\}}}=$ $r_{x y}$

$$
\begin{aligned}
& =\frac{15108}{\sqrt{(25611)(24392)}} \\
& =\frac{15108}{\sqrt{624703512}} \\
& =\frac{15108}{24994,07} \\
& =0,604
\end{aligned}
$$$$
3161808-3146700
$$$$
\sqrt{\{3451812-3426201\}\{2914392-2890000\}}
$$

Dari hasil perhitungan diperoleh $r_{\text {hitung }}$ sebesar 0,604 , sedangkan $r_{\text {tabel }}$ diperoleh sebesar 0,297 dengan derajat kebebasan $5 \%$ dengan demikian $r_{\text {hitung }}>$ $r_{\text {tabel }}$ yaitu 0,604 $>0,297$. Dari pengujian hipotesis dalam penelitian ini adalah:

$\mathrm{Ha}=$ Ada hubungan strategi perekrutan dengan anggota baru K-link di Stockist Center Padangsidimpuan diterima

Ho = Tidak ada hubungan strategi perekrutan dengan anggota baru $K$ link di Stockist Center Padangsidimpuan ditolak

Dengan kaidah pengujian

$\mathrm{Ha}: r \neq 0$

$\mathrm{H}_{0}: \mathrm{r}=0$

Sedangkan arti harga $r_{\text {hitung }}$ sebesar

0,604 diinterpretasi terhadap tabel interpretasi koefisien korelasi nilai $r$ dimana nilai $r_{\text {hitung }}$ berada pada interval koefisien $0,60-0,799$ dengan tingkat hubungan kuat.

Selanjutnya untuk menguji signifikansi koefisien korelasi ganda di atas, dapat juga dihitung dengan rumus:

$$
\begin{aligned}
& t=\frac{r \sqrt{n-2}}{\sqrt{1-r^{2}}} \\
& t=\frac{0,604 \sqrt{52-2}}{\sqrt{1-(0,604)^{2}}} \\
& t=\frac{0,604 \sqrt{50}}{\sqrt{1-0,36538}} \\
& t=\frac{(0,604)(7,07107)}{\sqrt{0,634624}} \\
& t=\frac{4,2742015}{0,7966329} \\
& t=5,37
\end{aligned}
$$

Jadi harga $t_{\text {hitung }}=5,37$ harga tersebut selanjutnya dikonsultasikan dengan harga $t_{\text {tabel }}$ dengan didasarkan pada $\mathrm{dk}=52-2=50$ sehingga $t_{\text {tabel }}$ sebesar 1,67. Dengan demikian diperoleh bahwa $t_{\text {hitung }}>t_{\text {tabel }}$ atau $5,37>1,67$ dengan demikian ada pengaruh strategi perekrutan dengan anggota baru K-link di Stockist Center Padangsidimpuan.

Sedangkan untuk menyatakan besar kecilnya sumbangan variabel $X$ terhadap $Y$ dapat ditentukan dengan rumus koefisien diterminan sebagai berikut: $\mathrm{KP}=$ $r^{2} \times 100 \%$

$\mathrm{KP}=0,604^{2} \times 100 \%$

$\mathrm{KP}=0,365 \times 100 \%$

$\mathrm{KP}=36,5 \%$

Berdasarkan hasil perhitungan nilai Koefisien Determinasi, diperoleh nilai kontribusi variabel $X$ (strategi perekrutan anggota) terhadap variabel $Y$ (anggota baru) adalah sebesar $36,5 \%$ dengan anggota baru K-link di Stockist Center Padangsidimpuan.

\section{KESIMPULAN}

Dari hasil penelitian yang dilaksanakan dapat diambil kesimpulan sebagai berikut: 
1. Hasil penelitian tentang strategi perekrutan anggota baru diketahui bahwa sebanyak 105 jawaban responden memilih Sangat puas, memilih Puas sebanyak 199 jawaban, Cukup puas sebanyak 124 jawaban, Kurang puas sebanyak 66 jawaban dan Tidak puas sebanyak 26. Dengan demikian dapat disimpulkan bahwa responden lebih banyak menjawab cukup puas dengan demikian strategi perekrutan anggota baru memuaskan.

2. Hasil penelitian tentang angota baru diketahui bahwa sebanyak 58 jawaban responden memilih Sangat puas, memilih Puas sebanyak 184 jawaban, Cukup puas sebanyak 147 jawaban, Kurang puas sebanyak 102 jawaban dan Tidak puas sebanyak 29. Dengan demikian dapat disimpulkan bahwa responden lebih banyak menjawab cukup puas dengan demikian anggota baru merasa puas akan mitra $K$-Link.

3. Dari hasil perhitungan diperoleh $r_{\text {hitung }}$ sebesar 0,604, sedangkan $r_{\text {tabel }}$ diperoleh sebesar 0,297 dengan derajat kebebasan $5 \%$ dengan demikian $r_{\text {hitung }}>$ $r_{\text {tabel }}$ yaitu 0,604 $>0,297$. Dari pengajuan hipotesis dalam penelitian ini adalah: Ada hubungan strategi perekrutan dengan anggota baru K-link di Stockis Center Padangsidimpuan diterima. Sedangkan arti harga $r_{\text {hitung }}$ sebesar 0,604 diinterpretasi terhadap tabel interpretasi koefisien korelasi nilai $r$ dimana nilai $r_{\text {hitung }}$ berada pada interval koefisien 0,60 - 0,799 dengan tingkat hubungan kuat. Dan hasil perhitungan diperoleh bahwa $t_{\text {hitung }}>t_{\text {tabel }}$ atau 5,37 $>$ 1,67 dengan demikian ada pengaruh strategi perekrutan dengan anggota baru K-link di Stockist Center Padangsidimpuan. Serta Hasil perhitungan nilai Koefisien Determinasi, diperoleh nilai kontribusi variabel $X$ (strategi perekrutan anggota) terhadap variabel $Y$ (anggota baru) adalah sebesar $36,5 \%$ dengan anggota baru $K$ link di Stockist Center Padangsidimpuan
Saran

Dari hasil pengujian hipotesis dan kesimpulan di atas dapat disarankan kepada:

1. Agar para mitra lebih mencari, atau memodifikasi strategi perekrutan anggota baru yang lebih baik dan menambah semangat untuk lebih giat mencari dan merekrut anggota baru serta memotivasi anggota baru untuk dapat berlanjut merekrut anggota baru dari linknya.

2. Anggota baru bersemangat dalam mengikuti pertemuan-pertemuan yang memungkinkan untuk menambah pengetahuan bagaimana merekrut dan mencari mitra yang banyak, seperti mengikuti seminar-seminar atau lebih sering datang ke stockist bertemu dengan mitra-mitra yang telah lebih dahulu menjadi anggota.

\section{DAFTAR PUSTAKA}

Akurinto Suharsimi, 2006, Prosedur Penelitian, Jakarta: Rineka Cipta.

Anoraga, Pandji, 2011, Pengantar Bisnis, Pengelolaaan Bisnis dalam Era Globalisasi, Jakarta: Rineka Cipta

Daryanto, 1998, Kamu Lengkap Bahasa Indonesia, Surabaya: Apollo Lestari.

Rachmawati, Ike Kusdyah, 2008 Manajemen Sumber Daya Manusia,Yogyakarta: Andi.

Riduwan, 2010, Belajar Mudah Penelitian Untuk Guru - Karyawan dan Peneliti Pemula, Bandung, Alfabeta

Sutrisno, Edy, 2011, Manajemen Sumebr Daya Manusia, Jakarta: Kencana.

Wirjana, Bernadine R. , 2007, Mencapai Manajemen Berkualitas, Organisasi, Kinerja, Program, Jakarta: Andi.

www.k-link.co.id 